\title{
Fatty acid profiles and desaturase-encoding genes are different in thermo- and psychrotolerant strains of the Bacillus cereus Group
}

\author{
Sara Esther Diomandé1,2, Marie-Hélène Guinebretière ${ }^{1,2,5^{*}}$, Benoit De Sarrau ${ }^{1,4}$, Christophe Nguyen-the ${ }^{1,2}$,
} Véronique Broussolle $e^{1,2}$ and Julien Brillard ${ }^{1,2,3}$

\begin{abstract}
Background: The Bacillus cereus Group consists of closely-related bacteria, including pathogenic or harmless strains, and whose species can be positioned along the seven phylogenetic groups of Guinebretière et al. (I-VII). They exhibit different growth-temperature ranges, through thermotolerant to psychrotolerant thermotypes. Among these, B. cytotoxicus is an atypical thermotolerant and food-poisoning agent affiliated to group VII whose thermotolerance contrasts with the mesophilic and psychrotolerant thermotypes associated to the remaining groups I-VI. To understand the role of fatty acid (FA) composition in these variable thermotypes (i.e. growth behavior vs temperatures), we report specific features differentiating the FA pattern of B. cytotoxicus (group VII) from its counterparts (groups I-VI).

Findings: The FA pattern of thermotolerant group VII (B. cytotoxicus) displayed several specific features. Most notably, we identified a high ratio of the branched-chain FAs iso-C15/iso-C13 (i15/i13) and the absence of the unsaturated FA (UFA) C16:1(5) consistent with the absence of $\Delta 5$ desaturase DesA. Conversely, phylogenetic groups II-VI were characterized by lower i15/i13 ratios and variable proportions of C16:1(5) depending on thermotype, and presence of the DesA desaturase. In mesophilic group I, thermotype seemed to be related to an atypically high amount of C16:1(10) that may involve $\Delta 10$ desaturase DesB.

Conclusion: The levels of i15/i13 ratio, C16:1(5) and C16:1(10) UFAs were related to growth temperature variations recorded between thermotypes and/or phylogenetic groups. These FA are likely to play a role in membrane fluidity and may account for the differences in temperature tolerance observed in B. cereus Group strains.
\end{abstract}

Keywords: B. cereus Group, Fatty acids, Desaturases, Temperature tolerance

\section{Background}

In bacteria, the fatty acid (FA) composition of the cell membrane varies according to environmental conditions, as it is involved in bacterial adaptation to environmental changes such as temperature, pressure, and $\mathrm{O}_{2}$ availability [1-4]. Among these changes, the effect of temperature on bacterial FA composition is a prominent

\footnotetext{
*Correspondence: marie-helene.guinebretiere@avignon.inra.fr ${ }^{5}$ INRA, UMR408 SQPOV, Site Agroparcs, 228 route de l'Aérodrome, CS40509, 84914 Avignon Cedex 9, France

Full list of author information is available at the end of the article
}

focus of research. Desaturases responsible for producing unsaturated FAs (UFAs) have been shown to play a role in low-temperature adaptation. The effect of incorporation of low-melting-point UFAs is to maintain membrane fluidity under the physical stress due to cold [5-9]. The number of desaturases varies depending on species, e.g. two desaturases have been identified in Bacillus cereus stricto or ss [10] whereas B. subtilis counts only one known desaturase [11]. The FA composition of bacterial cells is also known to vary according to species, especially in Bacillus and related genera [12, 13], and has 
been included among important features for describing new taxa of the aerobic endospore-forming bacteria [14].

The Bacillus cereus Group (B. cereus sensu lato or sl) includes bacterial strains with a wide range of growth temperatures. These strains can be classified by growthtemperature range, from psychrotrophic to thermotolerant strains [15]. These ranges of growth temperatures fit with the seven major phylogenetic groups (I-VII) established by Guinebretière et al. $[15,16]$ in the $B$. cereus Group (see Table 1). This 7-macrogroup classification is the most complete phylogenetic description of the B. cereus Group and is coherent with all MLST, AFLP, MLEE and genomic data produced since 2004 in the literature [17]. It offers a unique setting to investigate the relation between temperature adaptation and hypothetical factors and can be used to resolve problems tied to effective species delimitation in the Group. Indeed, B. cereus $s l$ contains seven closely-related species that, although not all genomospecies, can be clearly positioned by reference to each other in the classification of Guinebretière et al. (Additional file 1). Some of them have been described on the basis of singular phenotypic or pathologic traits such as rhizoidal colonies (B. mycoides), psychrotolerance $(B$. weihenstephanensis), insecticidal properties (B. thuringiensis) [18], enterotoxins (B. cereus sensu ss) [19] and anthrax (B. anthracis) [20]. Only two are true genomospecies: the harmless species $B$. pseudomycoides (mesophilic group I) and the pathogenic species B. cytotoxicus (thermotolerant group VII) [21], both of which thus share a homogenous growth-temperature range. B. mycoides $/ B$. weihenstephanensis (psychrotolerant group $\mathrm{VI}$ ), and $B$. anthacis (a clonal lineage within the highly mesophilic group III) also have a homogenous growth-temperature range as they belong each to a unique phylogenetic group, whereas $B$. cereus ss and $B$. thuringiensis represent highly heterogeneous thermotypes across phylogenetic groups II-VI (Additional file 1) [15, 16].

Bacillus cytotoxicus, though relatively rare, is known as one of the most virulent pathogenic species of $B$. cereus $s l$ $[16,21]$. Its pathogenicity is mainly attributed to the greater expression and cytotoxic activity of the poreforming cytotoxin K1 (CytK-1) [22-25], a variant of the cytotoxin $\mathrm{K}$ found in many strains of $B$. cereus sl [16]. Bacillus cytotoxicus comprises solely thermotolerant strains $[15,21]$. In addition to all these particularities, B. cytotoxicus has been described as displaying a specific FA composition in B. cereus $s l$ [21]. However, this specific FA composition of $B$. cytotoxicus has actually only been validated with reference to 4 of the 7 phylogenetic groups, and the relation between FA composition and the various thermotypes found in $B$. cereus $s l$ has not yet been studied.
The aim of this study was to determine to what extent the FA composition of B. cytotoxicus (phylogenetic group VII) differs from that of all the other phylogenetic groups of the B. cereus Group, and to what extent these differences relate to the growth-temperature ranges of the groups. In addition, as desaturases are known to play a role in low-temperature adaptation through FA composition and membrane fluidity, we also investigated the presence of desaturase-encoding genes among the available $B$. cereus $s l$ genomes and the existence of a putative relation between their presence and the FA composition of strains exhibiting different thermotypes.

\section{Methods}

\section{Strains}

The studied strains are listed in Additional file 2 and were representative of all seven phylogenetic groups. Minimal growth temperature $\left(\mathrm{T}_{\min }\right)$ and maximal growth temperature $\left(\mathrm{T}_{\max }\right)$ were used to determine growth-temperature range $\left(\mathrm{T}_{\min }-\mathrm{T}_{\max }\right)$. Their group affiliation and growthtemperature range were determined in previous studies in 2008 and 2013 [15, 21]. As a rule, each phylogenetic group has its own growth-temperature range [15], as presented in Table 1 . In the previous work of 2008, $\mathrm{T}_{\min }$ and $\mathrm{T}_{\max }$ were determined using a standard test described in the Bergey's Manual [26], with temperature fluctuation of the incubators being not greater than $\pm 0.2^{\circ} \mathrm{C}$ for all tested temperatures.

All these strains are referenced in the previous works of 2008 and 2013 [15, 21].These strains have since been conserved in our Laboratory (UMR408 Collection) and the original sources are presented in Additional file 2.

\section{Thermotypes}

The thermotypes were determined from the growth-temperature ranges $\left(\mathrm{T}_{\min }-\mathrm{T}_{\max }\right)$ as the resulting phenotype, and are presented in Table 1 by reference to growth-temperature range.

\section{FA profiling}

The FA methyl esters (FAMEs) were extracted using the standardized MIDI protocol (http://www.microbialid.com/PDF/TechNote_101.pdf). Bacterial cells were obtained from culturing at $30^{\circ} \mathrm{C}$ (at or close to optimal conditions for all seven phylogenetic groups) on trypticase soy broth agar (TSBA, $30 \mathrm{~g}$ trypticase soy broth and $15 \mathrm{~g}$ Bacto agar; $\mathrm{l}^{-1}$ ) for $24 \mathrm{~h}$ as previously described [21]. After extraction, FAMEs were analyzed by gas chromatography-mass spectrometry (GC-MS) (Shimadzu QP2010 system), as previously described [27]. 


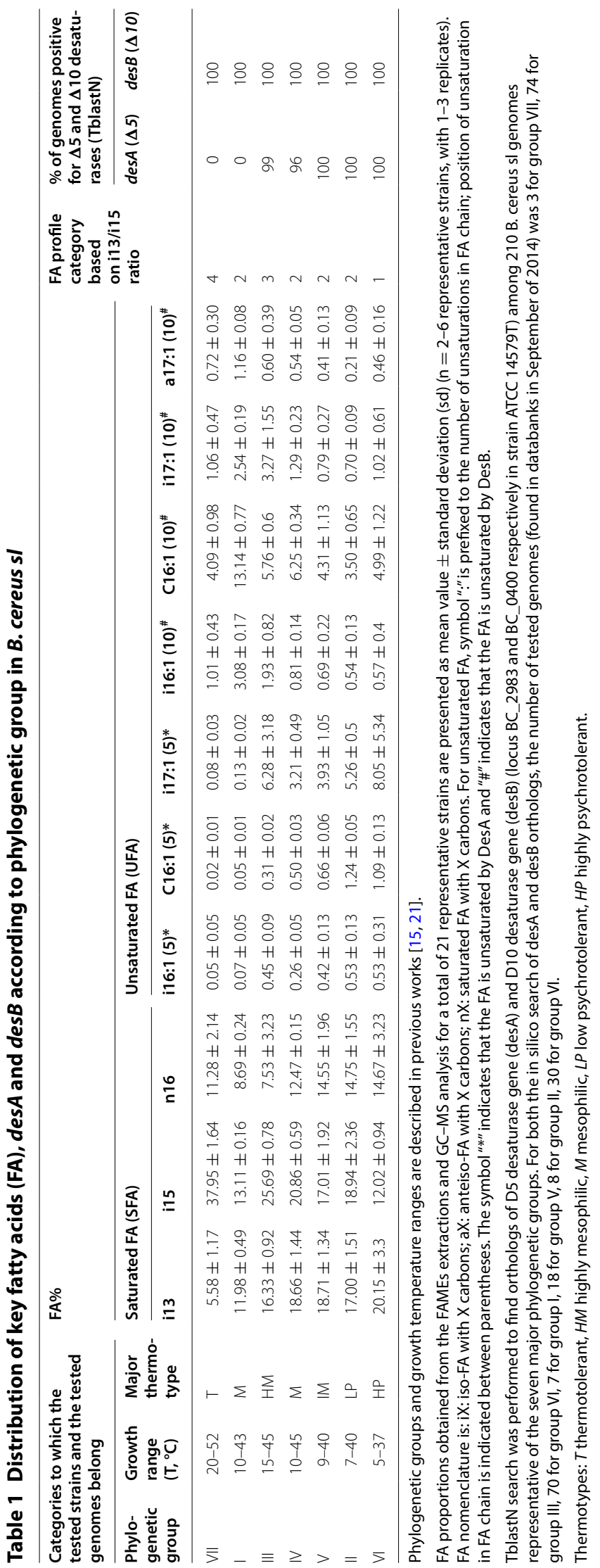




\section{In silico analysis}

A total of $210 \mathrm{~B}$. cereus $\mathrm{sl}$ genomes available in databases at the time of the search were used for this study. Genome affiliations to the phylogenetic groups were established previously [28], as described in [16], using pan $C$ sequence similarity.

Two desaturases have been described in B. cereus, i.e. DesA and DesB [10], which are responsible for two different types of unsaturation. The DesA enzyme adds a double bond in the $\Delta 5$-position of a saturated FA (SFA) while DesB creates an unsaturation in the $\Delta 10$-position of an SFA. The presence of each desaturase-encoding gene was thus investigated among all the available $B$. cereus $s l$ genomes. The search for $\operatorname{des} A$ and $\operatorname{des} B$ orthologs with reference to locus_tag $B C \_2983$ and $B C \_0400$, respectively, in the ATCC $14579 \mathrm{~T}$ genome (i.e. sequence loci described for desaturases in the ATCC 14579 genome) was performed via the Integrated Microbial Genomes (IMG) interface [29]. No other $\Delta 5$ or $\Delta 10$ desaturaseencoding genes have been reported in the $B$. cereus Group. First, candidate homologs were identified based on BLASTp similarities with a 1e-2 E-value cutoff and with low-complexity soft masking (-F'm S') turned on. Second, orthologous relationships between BC_2983 or $B C \_0400$ genes and their respective homologous genes in all other genomes were established through bidirectional best blast hits.

\section{Results and discussion}

FA composition in B. cereus sensu lato: general features

The B. cereus Group displays a specific overall FA pattern setting it apart from the other species of the Bacillus genus [21, 30], with short-chain branched FAs (12C and $13 \mathrm{C}$ ) and a characteristic predominance of iso-C13:0 (Additional file 2). Whatever the phylogenetic group analyzed, three major FAs were identified: iso-C15:0 (i15), iso-C13:0 (i13) and C16:0 (n16). For better visibility, only these three major SFAs and the 7 UFAs (previously linked to cold adaptation $[3,27]$ ) are listed in Table 1 . While the n16 SFA did not range widely according to thermotype, the proportion of the other two SFAs (i13 and i15) varied for the most sharply-contrasting thermotypes, i.e. the thermotolerant type (group VII, B. cytotoxicus), the highly mesophilic type (group III), and the highly psychrotolerant type (group VI). The SFA i15 accounted for more than $1 / 13.3$ of total FAs in group VII (B. cytotoxicus) and thus constituted a marker for this group.

\section{i15/i13 ratio as a rough indicator of thermotype}

We calculated the $115 / \mathrm{i} 13$ ratio, defined as proportion of iso-C15:0 divided by proportion of iso-C13:0, for strains belonging to each phylogenetic group (Fig. 1a).

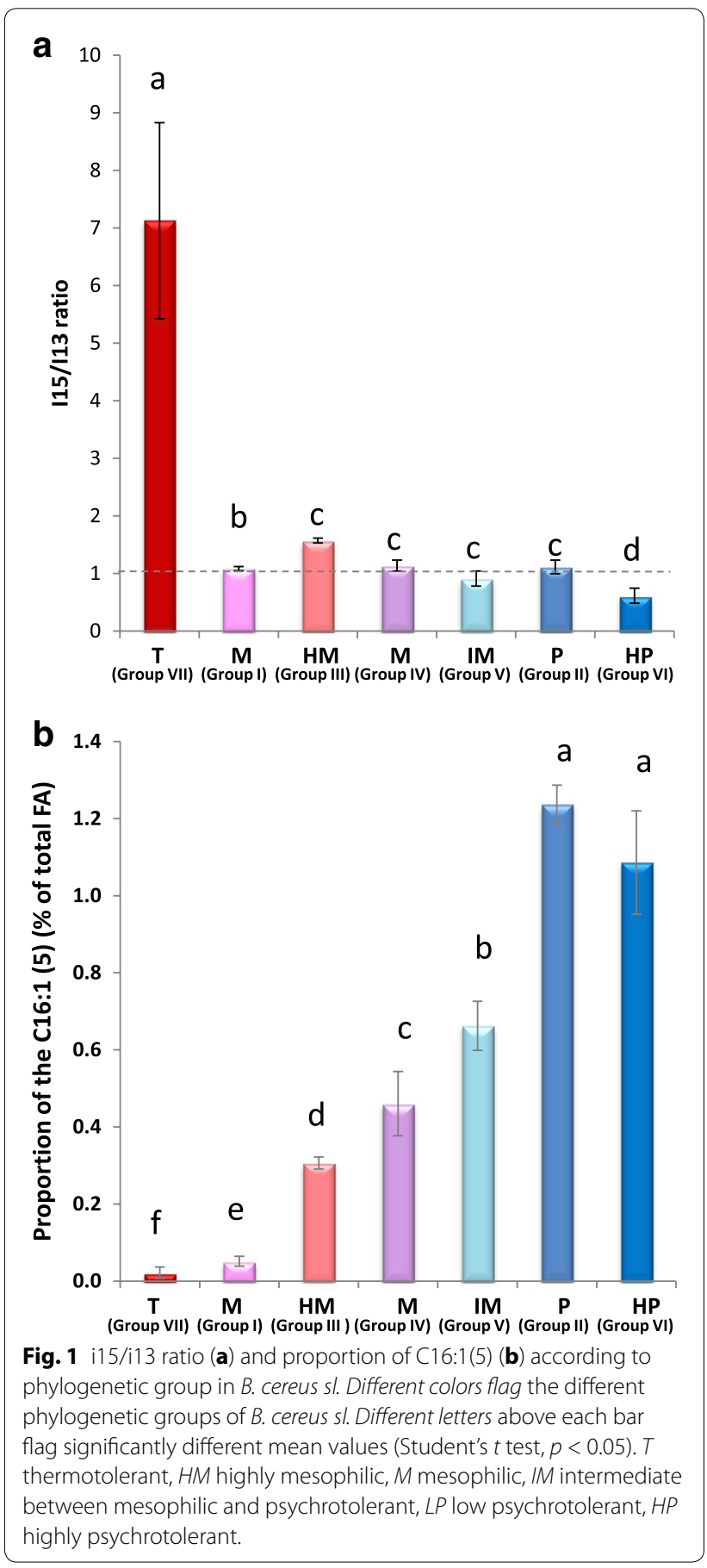

i15/i13 ratio was specifically very high in the thermotolerant strains of group VII (7.13 \pm 1.7 , Fig. 1a) but comparatively very low in the other groups (I-VI), with some variations: largely above 1 (1.57 \pm 0.04$)$ for the highly mesophilic strains of group III, largely below $1(0.61 \pm 0.13)$ for the highly psychrotolerant 
strains of group VI, and close to 1 in the remaining strains (groups I, II, V and IV). Taken together, these data strongly suggest that the $\mathrm{i} 15 / \mathrm{i} 13$ ratio criterion can roughly discriminate $B$. cereus $s l$ strains into 4 categories (Table 1): (1) highly psychrotolerant strains (group VI), (2) low psychrotolerant to mesophilic strains (groups II, V, IV, I), (3) highly mesophilic strains (group III), and (4) thermotolerant strains (group VII, B. cytotoxicus).

\section{Presence of $\Delta 5 / \Delta \mathbf{1 0}$-desaturases and proportion of C16:1(5) as an accurate indicator of thermotype in the most recent branch of $B$. cereus $s l$}

UFAs unsaturated at the $\Delta 5$ position were present in the most recent phylogenetic groups (II-VI, see Additional file 1) yet absent from thermotolerant group VII (B. cytotoxicus) and mesophilic group I (Table 1), particularly C16:1(5). We therefore searched for the presence of the genes encoding for the desaturases responsible for the synthesis of UFAs unsaturated at the $\Delta 5$ or $\Delta 10$ location (des $A$ and $\operatorname{des} B$ respectively) in this group of bacteria. The results indicated that, contrary to $\operatorname{des} B$, orthologs of $\operatorname{des} A$ were not found in all B. cereus sl genomes (Table 1): none of the genomes in groups I and VII contained an ortholog of desA gene. The $2.5-4 \%$ of negative genomes in groups III and IV may be due to information missing from draft genomes. However, in groups I (B. pseudomycoides strains) and VII (B. cytotoxicus strains), the ortholog of $\operatorname{des} A$ was truly absent, consistent with the near-zero concentration of $\Delta 5$ UFAs observed in groups I and VII.

Considering only groups II to VI, C16:1(5) proportion increased with thermotype, from the highly mesophilic to the highly psychrotolerant groups (with no significant difference between the two psychrotolerant groups II and VI) (Fig. 1b). Despite being produced in low amounts, C16:1(5) proportion appeared a good parameter to discriminate psychrotolerant thermotypes (groups II, VI) from other thermotypes and even to discriminate between mesophilic thermotypes (groups III, IV, V), including those that were not discriminated by i15/i13 ratio (groups II, V, IV).

Atypically in group-I strains, UFAs unsaturated at the $\Delta 10$ location were produced in higher proportions than in the other groups (Table 1), particularly C16:1(10), offsetting the lack of UFAs unsaturated at the $\Delta 5$ location. This difference presumably contributes to membrane fluidity and allows group I (B. pseudomycoides) to exhibit a mesophilic thermotype. In contrast to mesophilic group I (B. pseudomycoides), the thermotolerant group VII ( $B$. cytotoxicus) seems unable to offset this deficiency by producing larger amounts of UFAs unsaturated at the $\Delta 10$ location.

\section{FA composition and putative link with cold adaptation} in the B. cereus Group

Our study highlighted the relation between i15/i13 ratio and B. cereus Group thermotypes. Another study reported that proportion of $\mathrm{i} 13$ was strongly reduced in a B. cereus ATCC 14579 mutant displaying growth impairment at low temperature compared with its parental strain during growth at low temperature [27]. The i15/i13 ratio recalculated from these data [27] was much higher in the mutant than in the parental strain, emphasizing the putative role of a low i15/i13 ratio for psychrotolerance ability.

The C16:1(5) UFA presumably appeared with $\Delta 5$ desaturase DesA in the most recent branch of the phylogeny in B. cereus $s l$ containing groups II-VI (see Additional file 1). Its absence in phylogenetic groups I and VII indicates a link with the whole evolution of the $B$. cereus Group. Indeed, groups I and VII belong to two other independent branches at the base of the phylogenetic tree (see Additional file 1). Taken together, these results converge towards a differential process of evolution involving $\Delta 5$ UFAs for groups II-VI and $\Delta 10$ UFAs for group I. As group VII is basal to the evolutionary tree, followed by group I and then the remaining groups, we can posit that the ancestor of the B. cereus Group was devoid of $\Delta 5$ UFAs and went through adaptation in a few steps. The first step would involve an increase of $\Delta 10$ UFAs through group I. The second step would involve $\Delta 5$ UFAs through groups II-VI, with a more efficient adaptation from mesophily to psychrotolerance. This is also consistent with the absence of $\Delta 5$ desaturase (DesA) in groups I and VII. Interestingly, the same kind of configuration (absence in groups I and VII) was also observed for the two-component system CasK/R, which was recently described as playing a role in B. cereus-Group cold adaptation [28]. Through this observation, we can also posit that the lack of key genes such as casK/R and desA might be related to the inability of $B$. cytotoxicus strains to grow at temperatures below $20^{\circ} \mathrm{C}$ [21], and that these genes probably took part in a more complex mechanism of adaptation in the most recent branch of the phylogeny.

\section{Conclusion}

A link was established between the FA pattern of $B$. cereus $s l$ strains and ability or inability to grow at low temperature. The FA profile of B. cytotoxicus (group VII) is highly specific compared to that of the phylogenetic groups I-VI and is relatable to its atypical thermotolerance: high i15/i13 ratio, absence of UFAs unsaturated at the $\Delta 5$ location (particularly C16:1(5)), absence of a $\Delta 5$ desaturase (DesA). In contrast, the presence of $\Delta 5$ desaturase DesA and subtle amounts of C16:1(5) seem to be associated with an advanced mechanism of adaptation, 
resulting in a large panel of thermotypes through groups II-VI (from mesophily to psychrotolerance). Mesophilic strains of Group I seem to exhibit a specific intermediate state of evolution involving a fairly atypical amount of the $\Delta$ 10-desaturated C16:1(10).

\section{Availability of supporting data}

The datasets supporting the results of this article are included in Additional file 2.

\section{Additional files}

Additional file 1: Phylogeny of the B. cereus Group based on rrs and ITS1 gene sequence analysis, and position of species in this phylogeny. This file illustrates the position of the $B$. cereus s/ species over 7 major phylogenetic groups according to the classification scheme given in Guinebretière et al. 2008. It also shows the three main branches of evolution in the B. cereus Group.

Additional file 2: Fatty acid (FA) composition of $B$. cereus s/ strains belonging to the 7 phylogenetic groups. This file contains the raw FA composition data of the B. cereus s/ strains used to generate Table 1 and Figure 1.

\begin{abstract}
Abbreviations
$\Delta X$ desaturase: a desaturase adding a double bond on the Xth carboncarbon position of the fatty acid, counting from the carboxyl acid end; aX: anteiso-branched fatty acid with $x$ number of carbons; Cx: $y(z)$ : fatty acid with $x$ number of carbons and $y$ number of unsaturation(s) at location $z$; CytK1: cytotoxin K1; FA: fatty acid; FAME: fatty acid methyl ester; HM: highly mesophilic; HP: highly psychrotolerant; IM: intermediate between mesophilic and psychrotolerant; i15: iso-C15:0; i13: iso-C13:0; iX: iso-branched fatty acid with $\times$ number of carbons; M: mesophilic; n16: C16:0; nX: saturated fatty acid with $\times$ number of carbons; P: psychrotolerant; sd: standard deviation; ss: sensu stricto; sl: sensu lato; T: thermotolerant; UFA: unsaturated fatty acid; $x \mathrm{C}: \mathrm{x}$ carbon molecule(s).
\end{abstract}

\section{Authors' contributions}

SD organized and drafted the manuscript, analyzed the acquired data, performed the statistical analysis, interpreted the results and contributed to the write-up of the results. MHG conceived the study design, performed FAMEs extraction, contributed to data analysis and interpretation of results, and organized and edited the manuscript. BDS performed GC-MS analysis and extracted the data. CNT and VB were involved in editing and writing up the final version of the manuscript. JB supervised the analysis and interpretation of the outcomes and was involved in writing up the different versions of the manuscript. All the authors read and approved the final manuscript.

\section{Author details}

1 INRA, UMR408 Sécurité et Qualité des Produits d'Origine Végétale, 84000 Avignon, France. ${ }^{2}$ Université d'Avignon, UMR408 Sécurité et Qualité des Produits d'Origine Végétale, 84000 Avignon, France. ${ }^{3}$ INRA, UMR 1333 DGIMI, Université Montpellier, 34095 Montpellier Cedex 5, France. ${ }^{4}$ Present Address: Xurian Environnement, ZAE Béziers Ouest, rue du Jéroboam, 34500 Béziers, France. ${ }^{5}$ INRA, UMR408 SQPOV, Site Agroparcs, 228 route de l'Aérodrome, CS40509, 84914 Avignon Cedex 9, France.

\section{Acknowledgements}

The authors thank the INRA-MICA department and Provence-Alpes-Côte d'Azur Regional Council for providing financial support for S.D.'s PhD.

\section{Compliance with ethical guidelines}

\section{Competing interests}

The authors declare that they have no competing interests.
Received: 14 November 2014 Accepted: 22 July 2015

Published online: 31 July 2015

\section{References}

1. Yano Y, Nakayama A, Ishihara K, Saito H (1998) Adaptive changes in membrane lipids of barophilic bacteria in response to changes in growth pressure. Appl Environ Microbiol 64:479-485

2. Sinensky M (1971) Temperature control of phospholipid biosynthesis in Escherichia coli. J Bacteriol 106:449-455

3. de Sarrau B, Clavel T, Clerte C, Carlin F, Ginies C, Nguyen-The C (2012) Influence of anaerobiosis and low temperature on Bacillus cereus growth, metabolism, and membrane properties. Appl Environ Microbiol 78:1715-1723

4. Beranova J, Mansilla MC, de Mendoza D, Elhottova D, Konopasek I (2010) Differences in cold adaptation of Bacillus subtilis under anaerobic and aerobic conditions. J Bacteriol 192:4164-4171

5. Fulco AJ (1967) The effect of temperature on the formation of delta 5-unsaturated fatty acids by bacilli. Biochim Biophys Acta 144:701-703

6. Fulco AJ (1972) The biosynthesis of unsaturated fatty acids by Bacilli: III. Uptake and utilization of exogenous palmitate. J Biol Chem 247:3503-3510

7. Fulco AJ (1969) The biosynthesis of unsaturated fatty acids by Bacilli: I. Temperature induction of the desaturation reaction. J Biol Chem 244:889-895

8. Kaneda T (1972) Positional preference of fatty acids in phospholipids of Bacillus cereus and its relation to growth temperature. Biochim Biophys Acta 280:297-305

9. Bredeston LM, Marciano D, Albanesi D, De Mendoza D, Delfino JM (2011) Thermal regulation of membrane lipid fluidity by a two-component system in Bacillus subtilis. Biochem Mol Biol Educ 39:362-366

10. Chazarreta Cifre L, Alemany M, de Mendoza D, Altabe S (2013) Exploring the biosynthesis of unsaturated fatty acids in Bacillus cereus ATCC 14579 and functional characterization of novel acyl-lipid desaturases. Appl Environ Microbiol. 79:6271-6279

11. Aguilar PS, Hernandez-Arriaga AM, Cybulski LE, Erazo AC, de Mendoza D (2001) Molecular basis of thermosensing: a two-component signal transduction thermometer in Bacillus subtilis. EMBO J 20:1681-1691

12. Kampfer $P$ (1994) Limits and possibilities of total fatty acid analysis for classification and identification of Bacillus species. Syst Appl Microbiol 17:86-98

13. Kampfer $P$ (2002) Whole-cell fatty acid analysis in the systematics of Bacillus and related genera. In: Berkeley R, Heyndrickx M, Logan N, DeVos P (eds) Applications and Systematics of Bacillus and Relatives, pp 271-299

14. Logan NA, Berge O, Bishop AH, Busse HJ, De Vos P, Fritze D et al (2009) Proposed minimal standards for describing new taxa of aerobic, endospore-forming bacteria. Int J Syst Evol Microbiol 59:2114-2121. doi:10.1099/ijs.0.013649-0

15. Guinebretière $M-H$, Thompson FL, Sorokin A, Normand P, Dawyndt P, Ehling-Schulz M et al (2008) Ecological diversification in the Bacillus cereus Group. Environ Microbiol 10:851-865. doi:10.1111/j.1462-2920.2007.01495.x

16. Guinebretiere MH, Velge P, Couvert O, Carlin F, Debuyser ML, Nguyen-The C (2010) Ability of Bacillus cereus Group strains to cause food poisoning varies according to phylogenetic affiliation (groups I to VII) rather than species affiliation. J Clin Microbiol 48:3388-3391

17. Tourasse NJ, Helgason E, Klevan A, Sylvestre P, Moya M, Haustant M et al (2011) Extended and global phylogenetic view of the Bacillus cereus group population by combination of MLST, AFLP, and MLEE genotyping data. Food Microbiol 28:236-244. doi:10.1016/j.fm.2010.06.014

18. Bravo A, Likitvivatanavong S, Gill SS, Soberon M (2011) Bacillus thuringiensis: a story of a successful bioinsecticide. Insect Biochem Mol Biol 41:423-431

19. Stenfors Arnesen L, Fagerlund A, Granum P (2008) From soil to gut: Bacillus cereus and its food poisoning toxins. FEMS Microbiol Rev 32:579-606

20. Kalamas AG (2004) Anthrax. Anesthesiol Clin N Am 22:533-540

21. Guinebretiere MH, Auger S, Galleron N, Contzen M, De Sarrau B, De Buyser ML et al (2013) Bacillus cytotoxicus sp. nov. is a novel thermotolerant species of the Bacillus cereus Group occasionally associated with food poisoning. Int J Syst Evol Microbiol 63:31-40 
22. Lund T, De Buyser M-L, Granum PE (2000) A new cytotoxin from Bacillus cereus that may cause necrotic enteritis. Mol Microbiol 38:254-261. doi:10.1046/j.1365-2958.2000.02147.x

23. Fagerlund A, Ween O, Lund T, Hardy SP, Granum PE (2004) Genetic and functional analysis of the cytK family of genes in Bacillus cereus. Microbiology 150:2689-2697

24. Fagerlund A, Brillard J, Furst R, Guinebretiere MH, Granum PE (2007) Toxin production in a rare and genetically remote cluster of strains of the Bacillus cereus group. BMC Microbiol 7:43

25. Brillard J, Lereclus D (2004) Comparison of cytotoxin cytK promoters from Bacillus cereus strain ATCC 14579 and from a B. cereus food-poisoning strain. Microbiology-Sgm. 150:2699-2705. doi:10.1099/mic.0.27069-0

26. Claus D, Berkeley RCW (1986) Genus Bacillus Cohn 1872, 174 ${ }^{\mathrm{AL}}$. In: Sneath PHA, Mair NS, Sharpe ME, Holt JG (eds) Bergey's manual of systematic bacteriology. Williams \& Wilkins, Baltimore, pp 1105-1139
27. Brillard J, Jehanno I, Dargaignaratz C, Barbosa I, Ginies C, Carlin F et al (2010) Identification of Bacillus cereus genes specifically expressed during growth at low temperatures. Appl Environ Microbiol 76:2562-2573

28. Diomandé $\mathrm{S}$, Chamot $\mathrm{S}$, Antolinos V, Vasai F, Guinebretière $\mathrm{M}-\mathrm{H}$, Bornard I et al (2014) The CasKR two-component system is required for growth at low temperature of mesophilic and psychrotolerant Bacillus cereus strains. Appl Environ Microbiol. doi:10.1128/aem.00090-14

29. Markowitz VM, Chen IM, Palaniappan K, Chu K, Szeto E, Grechkin Y et al (2012) IMG: the Integrated Microbial Genomes database and comparative analysis system. Nucleic Acids Res. 40:D115-D122

30. Song Y, Yang R, Guo Z, Zhang M, Wang X, Zhou F (2000) Distinctness of spore and vegetative cellular fatty acid profiles of some aerobic endospore-forming bacilli. J Microbiol Methods 39:225-241
Submit your next manuscript to BioMed Central and take full advantage of:

- Convenient online submission

- Thorough peer review

- No space constraints or color figure charges

- Immediate publication on acceptance

- Inclusion in PubMed, CAS, Scopus and Google Scholar

- Research which is freely available for redistribution

Submit your manuscript at www.biomedcentral.com/submit 